\title{
Using a Nonlinear Model Predictive Control Strategy for the Efficient Operation of a Solar-powered Membrane Distillation System
}

\author{
Juan D. Gil ${ }^{1}$, Lidia Roca ${ }^{2}$, Alba Ruiz-Aguirre ${ }^{2}$, Guillermo Zaragoza ${ }^{2}$, José Luis Guzmán ${ }^{1}$ and Manuel Berenguel ${ }^{1}$
}

\begin{abstract}
This paper presents an optimal operation strategy in terms of thermal efficiency and distillate flux production for a Solar Membrane Distillation (SMD) system. Firstly, a study of the Membrane Distillation (MD) module is presented, revealing the optimal operation strategy. Secondly, a hierarchical control system with two layers is developed and tested. The upper layer consists on a Nonlinear Model Predictive Control (NMPC) scheme which allows us to obtain the maximum temperature at the inlet of the MD module, by optimizing the use of solar energy. The lower layer is composed by a direct control system that is in charge of reaching the setpoint calculated by the upper layer. Simulation results are shown in order to demonstrate the effectiveness of this control approach.
\end{abstract}

\section{INTRODUCTION}

SMD is a promising desalination technology that is being investigated to alleviate the freshwater shortage in remote areas with good solar irradiance conditions and brackish or seawater access. This technology stands out for its autonomous features such as simplicity and low grade thermal energy requirements, which make it a feasible solution to develop stand-alone systems for small-medium scale desalination applications [1].

MD consists of a thermally-driving process, in which the driving force is the vapour pressure difference between both sides of a hydrophobic-microporous membrane, achieved by a temperature difference. This process can treat solutions with high salinity, without a strong feed water chemical pretreatment as in other desalination technologies. Several MD configurations can be adopted according to the vapour pressure difference across the membrane, being the Air-Gap Membrane Distillation (AGMD), the one used in this paper, one of the most employed. In this configuration, a band of stagnant air is interposed between the membrane and the condensation surface, reducing the heat losses produced in other configurations [2].

Despite its range of good features, SMD has several technical challenges, that have prevented till now to become commercialized [3]. Ones of the most significant drawbacks are the low thermal efficiency and the low distillate flux

\footnotetext{
*Research supported by the projects DPI2014-56364-C2-1/2-R (ENERPRO) and DPI2014-55932-C2-1-R (PROBIOREN) financed by the Spanish Ministry of Economy and Competitiveness and ERDF founds.

${ }^{1}$ Centro Mixto CIESOL, ceiA3, Universidad de Almería, Departamento de Informática. Ctra. Sacramento s/n, Almería 04120, Spain; \{juandiego.gil,joseluis.guzman,beren\}@ual.es

${ }^{2}$ Centro Mixto CIESOL, CIEMAT-Plataforma Solar de Almería, Ctra. de Senés km. 4,5 Tabernas 04200, Almería 04120, Spain; \{alba.ruiz,lidia.roca,guillermo.zaragoza\}@psa.es
}

production. Apart from these problems, it should be taken into consideration the unpredictable and intermittent nature of solar energy. Hence, to develop independent desalination systems, it is required the implementation of optimal control strategies able to manage the energy provided by the sun, in order to maximize the plant efficiency.

Until now, there are few works dealing with the optimization of SMD systems with respect to thermal efficiency and distillate flux production. In [4], regression models are proposed to predict a specific performance index that takes into account the energy consumption as function of different variables. Then, an optimization problem is formulated in order to find optimal solutions, in terms of temperature and flow rate, maximizing the thermal efficiency. A nondominated sorting genetic algorithm is presented in [5] to maximize the thermal efficiency and the distillate production, making use of a regression model obtained by the response surface methodology. However, these two works do not deal with the optimal automatic operation of the facility. In this sense, two interesting automatic approaches are [6] and [7], where a control system using conventional Proportional Integral (PI) controllers is proposed in order to track optimal operation conditions calculated by means of an optimization study. The first work addressing an optimizing control system is [8], in which a neural network-based feedforward optimal control system is proposed to maximize the daily production of distillate.

This paper is focused on the development of a hierarchical control strategy of two layers trying to ensure an optimal automatic operation of the facility, maximizing the distillate production and the thermal efficiency. The upper layer includes a Practical Nonlinear Model Predictive Control (PNMPC) strategy [9] that provides temperature and flow rate setpoints for the heat generation SMD circuit. Besides, a Double Exponential Smoothing (DES) technique has been used to perform irradiance estimation, as suggested in [10]. On the other hand, the lower layer consists of a direct control system [11], [12] containing PI and feedforward controllers that are in charge of tracking the references calculated by the upper layer. This hierarchical control approach has been tested in simulation with a nonlinear simulation model of the MD-solar pilot plant located at Plataforma Solar de Almería (PSA, www.psa.es), Spain. The preliminary results obtained have been compared with a case without the PNMPC strategy in order to analize the advantages of the proposed technique. 


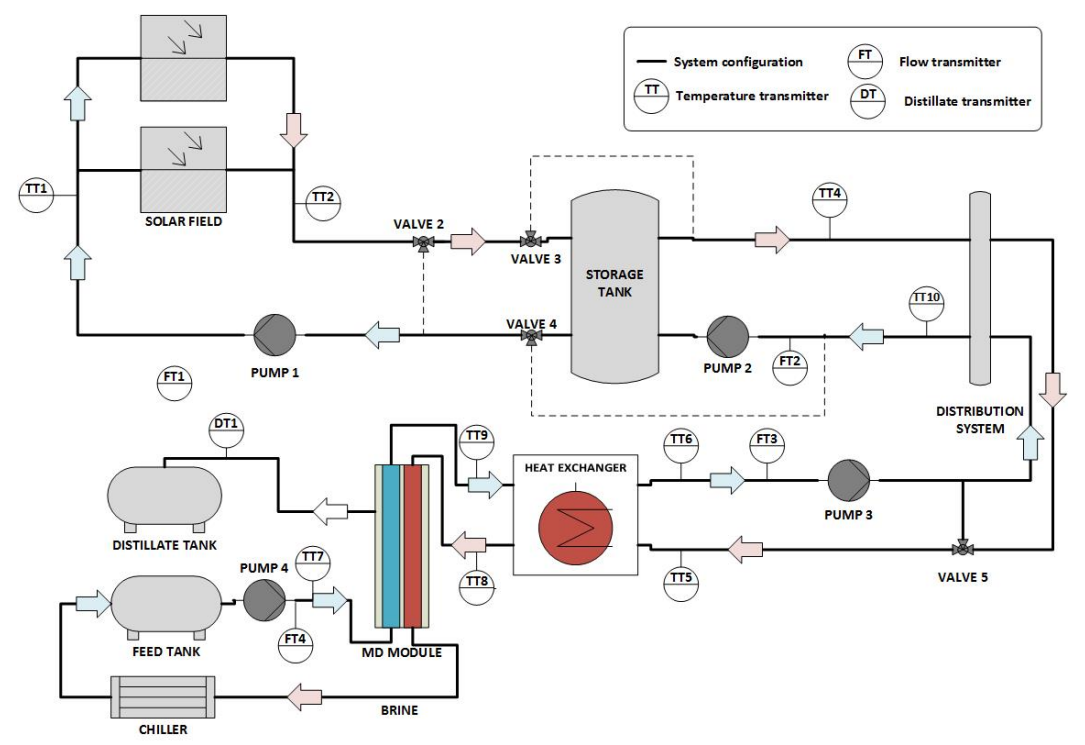

Fig. 1. Schematic diagram of the plant.

\section{SMD PLANT}

The schematic diagram of the test-bed facility at PSA is shown in Fig. 1. The thermal energy required to the distillation process is supplied by a solar thermal field, consisting on Flat-Plate Collectors. In this work, it is assumed that there are not other thermal sources apart from the solar field. This field is connected to a thermal storage tank, which is used as energy buffer in order to balance irradiance disturbances and transients. A distribution system is available to couple the tank and the AGMD module, which has its own heat exchanger. Finally, the heat exchanger is employed for heating cold sea water with the circulation fluid coming from the heat generation circuit. A complete description of the system is presented in [1] and [13].

\section{SYSTEM MODELING}

The model of the heat generation circuit was already presented and validated in [11], [12], [14]. This model includes a lumped-parameters model of the solar field according to [15], a stratified model of the storage tank based on an energy balance [16], and a first principles-based model of the heat exchanger [17]. Static energy balances were considered to model the distribution system and valves and transfer functions experimentally obtained were used to model pumps. The equations of this model are not included in this work due to the lack of space.

On the other hand, an experimental campaign has been carried out in order to obtain a static model of the AGMD module distillate production and $\triangle \mathrm{T}$, which is the temperature difference between the inlet evaporator channel temperature TT8 and the outlet condensation channel temperature TT9 (see Fig. 1). Thereby, several tests keeping static conditions during one hour have been performed, following the experimental procedure detailed in [13]. The salinity used was $35 \mathrm{~g} / \mathrm{L}$ which is the average salinity of the oceans. The model input variables are: i) feed flow rate (FT4 in Fig. 1) varying between 400 and $600 \mathrm{~L} / \mathrm{h}$, ii) evaporation channel inlet temperature (TT8 in Fig. 1) ranging between $60-80{ }^{\circ} \mathrm{C}$, and iii) condensation channel inlet temperature (TT7 in Fig. 1) varying between $20-30{ }^{\circ} \mathrm{C}$. The static equations calculated are given by:

$$
\begin{aligned}
& \mathrm{D}=24 \cdot(0.135+0.003 \cdot \mathrm{TT} 8-0.0204 \cdot \mathrm{TT} 7 \\
& -0.001 \cdot \mathrm{FT} 4+0.00004 \cdot \mathrm{TT} 8 \cdot \mathrm{FT} 4), \\
& \begin{aligned}
\triangle \mathrm{T} & =-0.739+0.078 \cdot \mathrm{TT} 8-0.067 \cdot \mathrm{TT} 7 \\
& +0.0019 \cdot \mathrm{FT} 4,
\end{aligned}
\end{aligned}
$$

where $\mathrm{D}$ is the distillate flux production $\mathrm{L} / \mathrm{min}$. The units are ${ }^{\circ} \mathrm{C}$ for the temperature and $\mathrm{L} / \mathrm{h}$ for the flow rate. The mean error for $\Delta \mathrm{T}$ is $0.176{ }^{\circ} \mathrm{C}$, being the maximum $0.3421{ }^{\circ} \mathrm{C}$ while the mean error for $\mathrm{D}$ is $0.476 \mathrm{~L} / \mathrm{min}$ and the maximum error is $1.33 \mathrm{~L} / \mathrm{min}$.

\section{OPTIMAL OPERATION}

Several performance indexes can be adopted to evaluate the plant thermal efficiency. In this case, the Specific Thermal Energy Consumption (STEC), which is the quantity of thermal energy required per volume unit of distillate produced, has been chosen:

$$
\mathrm{STEC}\left[\mathrm{kWh} / \mathrm{m}^{3}\right]=\frac{\mathrm{FT} 4 \cdot \rho_{\text {feed }} \cdot C_{p} \cdot(\mathrm{TT} 8-\mathrm{TT} 9)}{C_{f} \cdot \mathrm{D}},
$$

where $\rho_{\text {feed }}$ is the feed water density $\left(\mathrm{kg} / \mathrm{m}^{3}\right), C_{p}$ is the heat water capacity $\left(\mathrm{J} / \mathrm{kg} \cdot{ }^{o} \mathrm{C}\right)$, and $C_{f}$ is a conversion factor $\left(3.6 \cdot 10^{6} \mathrm{~s} \cdot \mathrm{W} / \mathrm{h} \cdot \mathrm{kW}\right)$.

$3 \mathrm{D}$ response surface plots have been used in order to reveal the optimal operation. STEC, $\triangle \mathrm{T}$ and $\mathrm{D}$ have been expressed as a function of the inlet evaporation channel temperature (TT8) and the feed flow rate (FT4), keeping the inlet condensation channel temperature (TT7) fixed at $25^{\circ} \mathrm{C}$ (what is normal when working with sea water). The 
distillate flux 3D response surface is shown in Fig. 2. It can be observed that increasing the feed flow rate (FT4) and the temperature (TT8), the distillate flux production augments. Notice that temperature affects more notably than flow rate.

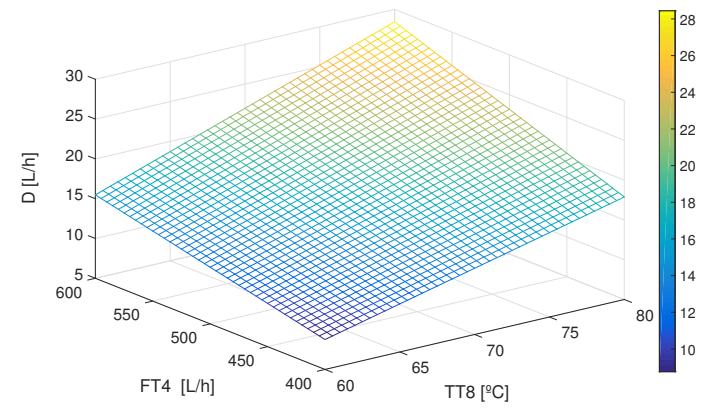

Fig. 2. 3D response surface plot of distillate flux.

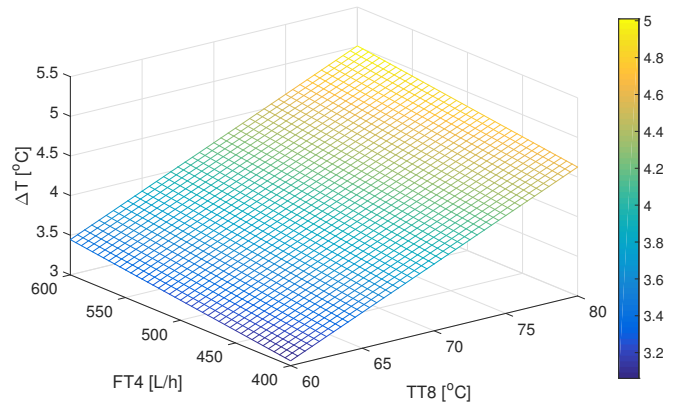

Fig. 3. 3D response surface plot of $\delta \mathrm{T}$.

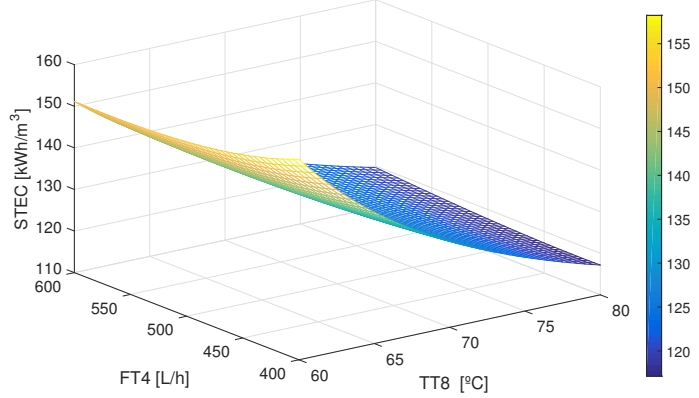

Fig. 4. 3D response surface plot of STEC.

On the other hand, according to Eq. 3, STEC is a function of $\triangle T$, FT4 and D. Fig. 3 and 4 show the effects of TT8 and FT4 on $\triangle \mathrm{T}$ and STEC. It can be seen that TT8 has more influence than FT4 in both STEC and $\triangle \mathrm{T}$. Therefore, when high TT8 is applied $\triangle \mathrm{T}$ increases, however $\mathrm{D}$ increases more significantly (see Fig. 2), thus decreasing STEC which means higher thermal efficiency.

\section{CONTROL SYSTEM ARCHITECTURE}

As has been analyzed, TT8 is the most significant variable influencing both STEC and distillate production. Therefore, the aim of the hierarchical control system (see Fig. 5) is to maximize the inlet evaporator temperature (TT8) in order to obtain an optimal operation of the system. For this purpose, a PNMPC strategy [9] has been adopted in the upper layer, using a simplified version of the SMD plant model commented in Section III. Notice that FT4 is not included in the upper layer and it will be fixed at $500 \mathrm{~L} / \mathrm{h}$ in order to carry out all the tests in the same conditions. A MPC technique has been chosen as it easily copes with dead times and disturbances, which are two of the main control challenges in this problem [18]. The lower layer is composed by a direct control system helping to maintain the main variables involved in the process near steady state conditions in spite of irradiance disturbances.

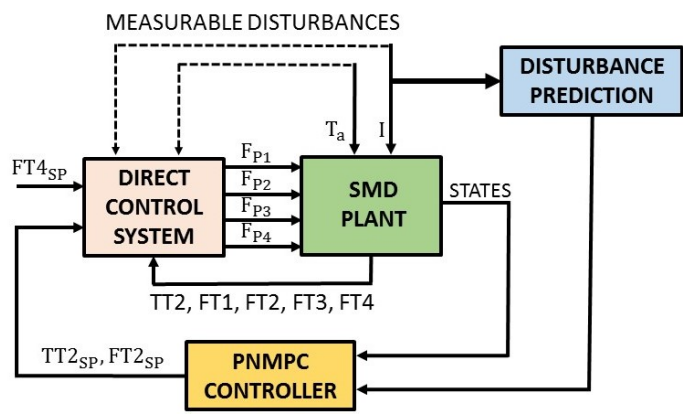

Fig. 5. Hierarchical control strategy scheme.

\section{A. Lower layer: Direct control system}

The direct control layer is composed by five loops and it was developed and tested in [11], [12], [14]. As it has been pointed out before, the objective of this control layer is to maintain near steady state conditions the main variables involved in the process. Thus, the controlled variables are the outlet solar field temperature (TT2) and the feed flow rates FT2, FT3 and FT4, and the main disturbances are ambient temperature $\left(\mathrm{T}_{a}\right)$ and global irradiance (I). Firstly, TT2 is controlled by acting in the input frequency of pump $1\left(\mathrm{~F}_{\mathrm{P} 1}\right)$, using a cascade control loop. Besides, a feedforward using a static version of the solar field model (see Section III) allows to reject irradiance and ambient temperature disturbances. Secondly, three PI controllers are employed to control the feed flow rates FT2, FT3 and FT4 by means of theirs input frequency $\mathrm{F}_{\mathrm{P} 2}, \mathrm{~F}_{\mathrm{P} 3}$ and $\mathrm{F}_{\mathrm{P} 4}$. An antiwindup scheme was added to all control loops. The direct control layer was implemented using a sample time of 1 second. This value has been chosen to detect irradiance changes quickly. It should be mentioned that the fifth loop is in charge of controlling the temperature at the entrance of the heat exchanger by acting in valve 5 . However, it is not used in this work, and valve 5 is kept fully opened.

\section{B. Upper layer: PNMPC strategy}

Since the only thermal energy source is the solar field, the key to the optimal operation strategy is the proper management of the thermal energy stored in the tank. By acting on both the outlet solar field temperature control 
loop and the feed flow rate FT2 control loop, the thermal powers to load and unload the tank can be controlled. So, the PNMPC strategy will provide appropriate setpoints to the outlet solar field temperature (TT2 $2_{\mathrm{SP}}$ ) and to the feed flow rate FT2 $\left(\mathrm{FT} 2_{\mathrm{SP}}\right)$ in order to maximize the inlet evaporator temperature (TT8), which is the most significant variable to maximize the thermal efficiency and the distillate production according to Section IV. A PNMPC strategy has been adopted to sort out this problem [9], [19].

As all MPC techniques, PNMPC makes use of a prediction vector $\hat{\mathbf{Y}}$ that includes the future outputs for a specific horizon $N$, as a function of the future movements of the control signal $\boldsymbol{\Delta} \mathbf{U}$ :

$$
\hat{\mathbf{Y}}=\mathbf{F}+\mathbf{G} \cdot \Delta \mathbf{U}
$$

where $\mathbf{F}$ is the free response and $\mathbf{G} \cdot \boldsymbol{\Delta} \mathbf{U}$ is the forced response. In classical MPC algorithms, $\hat{\mathbf{Y}}$ is estimated as a function of a linear model of the system. However, in PNMPC, $\hat{\mathbf{Y}}$ is estimated using a simplified version of the SMD model (Section III). For this simplified version, difference equations have been used for the solar field and the storage tank models. Therefore, following the procedure proposed in [9], the PNMPC strategy is employed to estimate both $\mathbf{F}$ and $\mathbf{G}$ at each sample time. The PNMPC formulation is given by:

$$
\hat{\mathbf{Y}}=\mathbf{F}+\mathbf{G}_{\mathrm{PNMPC}} \cdot \boldsymbol{\Delta} \mathbf{U},
$$

where

$$
\begin{aligned}
\boldsymbol{\Delta} \mathbf{U} & =\left[\boldsymbol{\Delta} \mathbf{U}_{1} ; \boldsymbol{\Delta} \mathbf{U}_{2}\right], \\
\mathbf{F} & =f\left(\mathbf{y}_{\mathbf{p}}, \boldsymbol{\Delta} \mathbf{u}_{\mathbf{p}}\right), \\
\mathbf{G}_{\mathrm{PNMPC}} & =\left[\begin{array}{ll}
\frac{\partial \hat{\mathbf{Y}}_{\mathbf{1}}}{\partial \mathbf{U}_{\mathbf{1}}} & \frac{\partial \hat{\mathbf{Y}}_{\mathbf{1}}}{\partial \mathbf{U}_{\mathbf{2}}}
\end{array}\right],
\end{aligned}
$$

$\mathbf{y}_{\mathbf{p}}$ is a set of past and present values of output and $\Delta \mathbf{u}_{\mathbf{p}}$ is a set of past values of inputs. It should be mentioned that this technique provides only an approximation of the predictions, nevertheless it performs a better adjustment to the system behaviour than a linear model, since it uses linearized models at each sample time to compute $\mathbf{G}_{\text {PNMPC }}$ whereas the nonlinear model of the system is used to calculate $\mathbf{F}$ by keeping constants future control inputs.

1) Cost function: The control signal is calculated by minimizing a cost function, as in other MPC techniques. Therefore, an objective equation is formulated in order to determinate the future control changes $(\Delta \mathbf{U})$ maximizing TT8. The cost function takes into account the prediction of the output $\hat{\mathbf{Y}}$ and the future control changes $\Delta \mathbf{U}$ which are penalized by means of a weight factor $\lambda_{i}$ :

$$
J=-\sum_{j=1}^{N} \hat{Y}(k+j \mid k)+\sum_{i=1}^{2} \sum_{j=1}^{N_{u}} \lambda_{i}\left[\Delta U_{i}(k+j-1)\right]^{2}
$$

where $N$ is the prediction horizon, $N_{u}$ is the control horizon, $\hat{Y}(k+j \mid k)$ is the prediction of the output (TT8) calculated at sample time $k+j$ with the information acquired up to discrete-time instant $k, \lambda_{i}$ are the control signals weighting factors, where $\lambda_{1}$ is related with TT2 $2_{\mathrm{SP}}$ and $\lambda_{2}$ with FT2 $2_{\mathrm{SP}}$ and $\Delta U(k+j-1)$ is the future change in the control variable $i$, where $U_{1}$ is TT2 $2_{\mathrm{SP}}$ and $U_{2}$ is FT2 $2_{\mathrm{SP}}$.
2) Constraints: Three kinds of constraints have been considered to this optimization problem. The first constraint, Eq. 10, defines the maximum and minimum change allowed at each sample time in the control signals (slew rate ones). Steps higher than $5{ }^{\circ} \mathrm{C}$ are not recommended in the outlet solar field temperature, whereas the steps in FT2 are limited to $1 \mathrm{~L} / \mathrm{min}$. Both constraints ensure small setpoint movements trying to avoid security problems.

$$
\begin{gathered}
{\left[\begin{array}{c}
\Delta \mathbf{U}_{\mathbf{1}_{\text {min }}} \\
\boldsymbol{\Delta} \mathbf{U}_{\mathbf{2}_{\text {min }}}
\end{array}\right] \leq\left[\begin{array}{c}
\boldsymbol{\Delta} \mathbf{U}_{\mathbf{1}}(\mathrm{k}+\mathrm{j} \mid \mathrm{k}) \\
\boldsymbol{\Delta} \mathbf{U}_{\mathbf{2}}(\mathrm{k}+\mathrm{j} \mid \mathrm{k})
\end{array}\right] \leq\left[\begin{array}{c}
\boldsymbol{\Delta} \mathbf{U}_{\mathbf{1}_{\max }} \\
\boldsymbol{\Delta} \mathbf{U}_{\mathbf{2}_{\max }}
\end{array}\right]} \\
j=0, \ldots, N u-1
\end{gathered}
$$

The second constraint, Eq. 11, is related with the physical limits. On the one hand, pump 2 is able to provide flow rates ranging between $0-15 \mathrm{~L} / \mathrm{min}$. Moreover, the maximun and minimun temperatures $\left(\mathrm{T}_{\max }\right.$ and $\left.\mathrm{T}_{\min }\right)$ reachable by the field depend on the operational conditions. Therefore, they are calculated making use of a static version of the solar field model at each sample time.

$$
\begin{gathered}
{\left[\begin{array}{l}
\mathbf{U}_{\mathbf{1}_{\text {min }}} \\
\mathbf{U}_{\mathbf{2}_{\text {min }}}
\end{array}\right] \leq} \\
j=0, \ldots, N u-1 \\
\left.\quad \begin{array}{c}
\mathbf{U}_{\mathbf{1}}(\mathrm{k}+\mathrm{j} \mid \mathrm{k}) \\
\mathbf{U}_{\mathbf{2}}(\mathrm{k}+\mathrm{j} \mid \mathrm{k})
\end{array}\right] \leq\left[\begin{array}{l}
\mathbf{U}_{\mathbf{1}_{\max }} \\
\mathbf{U}_{\mathbf{2}_{\max }}
\end{array}\right] \\
j=0, \ldots, N u-1
\end{gathered}
$$

Finally, the output (TT8) is limited to $80{ }^{\circ} \mathrm{C}$ that is the maximum temperature allowed by materials of the membranes.

\section{Forecasting irradiance method.}

In order to improve the performance of the PNMPC strategy, both ambient temperature and global irradiance can be estimated using forecasting methods. Nevertheless, in this work only the global irradiance is estimated, since the ambient temperature has not significant changes along the sample time adopted. The forecasting method used in this work is the DES technique, following the ideas presented in [10]. The DES technique is given by the following two expressions:

$$
\begin{gathered}
S_{k}=\alpha y_{k}+(1-\alpha)\left(S_{k-1}+b_{k-1}\right), \\
b_{k}=\theta\left(S_{k}-S_{k-1}\right)+(1-\theta) b_{k-1},
\end{gathered}
$$

where $y_{k}$ is the real measure at instant $k$. The first expression provides the estimated value $\left(S_{k}\right)$, while the second expression provides the estimated trend $\left(b_{k}\right)$ that is calculated using actual and past values of the series. The constants $\alpha$ and $\theta \in(0,1)$ have been obtained by means of optimization techniques using experimental irradiance values. Thus, the estimation of $\mathrm{m}$ periods is given by:

$$
\hat{y}_{k+m}=S_{k}+m b_{k} .
$$

There are several ways to set the initial values for $S_{k}$ and $b_{k}$ [20]. In this case $S_{o}=y_{k}$ and $b_{o}=y_{k}-y_{k-1}$. This forecasting irradiance method has been implemented in this work for estimating $N$ future values according to the prediction horizon of the PNMPC controller. 

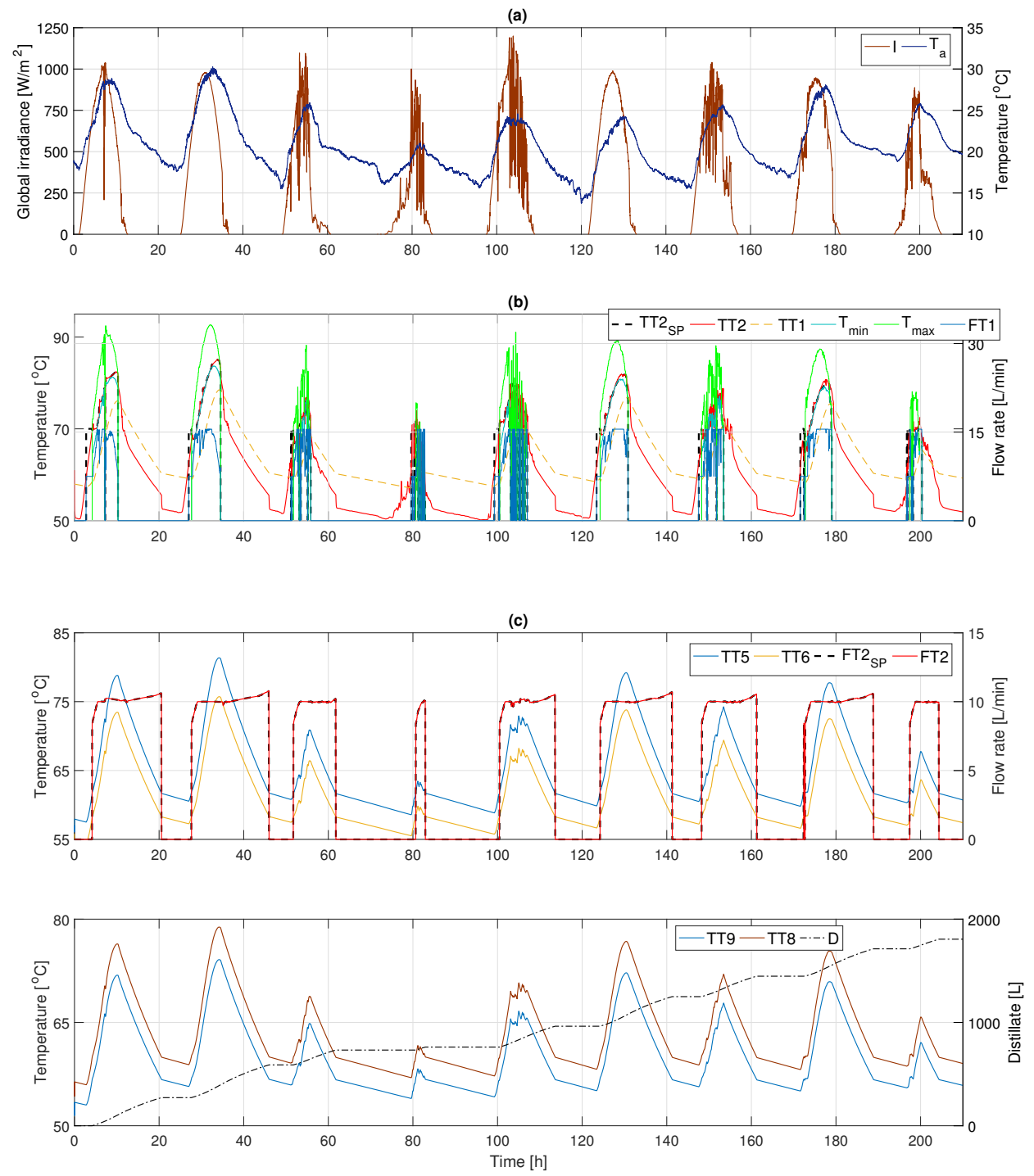

Fig. 6. Representative simulation results. All the variables are according to Fig. 1 and the subscripts has been presented in the text.

\section{Start-stop procedure}

A Start-stop procedure has been developed for both solar field and AGMD module. This procedure is executed with a sample time of 5 minutes (according to the one of the PNMPC technique) to avoid chattering problems. Due to the fact that solar field outlet temperature can be lower than the tank temperature depending on irradiance conditions and inlet temperature, the static model of the solar field is used in order to calculate the value of global irradiance which ensures that the solar field temperature is going to be higher than the one in the tank to avoid it cooling down. Therefore, pump 1 is turned on or off whether the real measure of global irradiance at the sample time $k$ is higher or lower than the value calculated by the model at the same instant, respectively. In the same way, the static model of the heat exchanger is used to ensure that the temperature coming from the tank allows to operate the AGMD module with $60{ }^{\circ} \mathrm{C}$.
Hence, the AGMD module is turned on when the required tank temperature is reached. Notice that the hierarchical control strategy is only executed when the AGMD module is started, so if only the solar field is operating, a fixed setpoint of $70{ }^{\circ} \mathrm{C}$ is imposed in $\mathrm{TT} 2_{\mathrm{SP}}$ until reaching the required temperature to turn on the AGMD module.

\section{RESULTS AND DISCUSSION.}

The proposed strategy has been tested in simulation, using meteorological data from PSA during nine days in October 2016 (see Fig. 6(a)). Several tests have been carried out with a sample time of 5 minutes and adopting different values to the prediction and control horizon. In all the tests, FT3 and FT4 have been fixed at $8.33 \mathrm{~L} / \mathrm{min}(500 \mathrm{~L} / \mathrm{h})$ and FT1 has been limited between 7.5-16.5 L/min due to physical limits in the water pump. Besides, FT2 has been limited between 8.33$15 \mathrm{~L} / \mathrm{min}$. The minimun value is imposed to avoid mixing in the distribution system, since if FT3 is higher than FT2 
the fluid coming from the tank is mixed with the cold fluid coming from the heat exchanger. The maximum value is the physical limit of the pump. The controller parameters adopted for the tests were $\lambda_{1}=0.1$ and $\lambda_{2}=1.1$, decided after simulating different combinations, whereas the DES technique parameters were $\alpha=0.9$ and $\theta=0.98$.

Fig. 6 shows one representative test with $N=N_{u}=5$. In Fig. 6(b) it can be observed the dynamical evolution of $\mathrm{TT}_{\mathrm{SP}}, \mathrm{TT} 1, \mathrm{TT} 2$ and its control signal which is FT1. Fig. 6(c) shows the evolution of FT2 ${ }_{\mathrm{SP}}$ and FT2 and the temperatures at the inlet and outlet of the heat exchanger. Finally, Fig. 6(d) represents the temperature at the entrance and outlet of the evaporator and condenser channel of the module and the accumulated distillate, assuming that it is not removed at the end of each day. In general, in Fig. 6(b) it can be seen that the PNMPC strategy maintains $\mathrm{TT} 2_{\mathrm{SP}}$ close to the lower limit (when FT1 is close to the maximum), trying to maximize the thermal power storage in the tank. Moreover it can be observed how the start-stop procedure turns on or off pump 1 when there are severe irradiance disturbances to avoid that cold fluid is stored in the tank. On the other hand, Fig. 6(c) shows that the PNMPC strategy maintains FT2 around $10 \mathrm{~L} / \mathrm{min}$ while the thermal energy coming from the solar field is high, and then, FT2 is smoothly increased when the energy is low, attempting to maximize TT8.

In order to stand out the advantages of the PNMPC technique, the preliminary simulation results (adopting differents prediction and control horizons) have been compared with a case, in which only the direct control layer is employed with static setpoints $\left(\mathrm{TT} 2_{\mathrm{SP}}=85{ }^{\circ} \mathrm{C}\right.$ and $\left.\mathrm{FT} 2_{\mathrm{SP}}=10 \mathrm{~L} / \mathrm{min}\right)$. Tab. I shows the results for the same nine days represented in Fig. 6(a). The accumulated distillate production and the mean STEC during the nine days have been employed as performance parameters.

TABLE I

COMPARISON OF RESULTS.

\begin{tabular}{l|l|l|l|l|}
\cline { 2 - 5 } & \multirow{2}{*}{ No } & \multicolumn{3}{|c|}{ YNMPC } \\
\cline { 2 - 5 } & & $N=N_{u}=1$ & $N=N_{u}=2$ & $N=N_{u}=5$ \\
\hline Distillate [L] & 1729 & 1804 & 1808 & 1806 \\
\hline STEC $\left[\mathrm{kWh} / \mathrm{m}^{3}\right]$ & 139.84 & 139.64 & 139.62 & 139.61 \\
\hline
\end{tabular}

As it can be observed, the distillate production is higher using the PNMPC strategy, obtaining around $9 \mathrm{~L}$ more each day. In the same way, the mean STEC is also lower for all the cases. Notice that the used facility is a small-scale pilot plant one. In potential industrial cases, these can be very relevant improvements for the daily operation. The computation time employed in solve the optimization problem for $N=N_{u}=5$ is $84.2 \mathrm{~s}$ (Intel i5-6500T CPU $2.50 \mathrm{GHz}$ with $8 \mathrm{~GB}$ of RAM).

\section{CONCLUSION AND FUTURE WORKS.}

This paper has addressed the application of a practical nonlinear model predictive control technique in a solar membrane distillation system, aimed at maximizing the distillate flux production and the thermal efficiency. Promising simulation results have been obtained revealing that both distillate production and thermal efficiency are significantly augmented by using the proposed technique.

Future works will be focused on testing this hierarchical control approach at the real facility, and also on studying the effects of adopting several cost functions which take into account economic costs associated to the production.

\section{REFERENCES}

[1] G. Zaragoza, A. Ruiz-Aguirre, and E. Guillén-Burrieza, "Efficiency in the use of solar thermal energy of small membrane desalination systems for decentralized water production," Applied Energy, vol. 130, pp. 491-499, 2014

[2] A. Alkhudhiri, N. Darwish, and N. Hilal, "Membrane distillation: a comprehensive review," Desalination, vol. 287, pp. 2-18, 2012.

[3] M. Khayet, "Solar desalination by membrane distillation: Dispersion in energy consumption analysis and water production costs (a review)," Desalination, vol. 308, pp. 89-101, 2013.

[4] M. Khayet and C. Cojocaru, "Air gap membrane distillation: Desalination, modeling and optimization," Desalination, vol. 287, pp. 138-145, 2012.

[5] Q. He, P. Li, H. Geng, C. Zhang, J. Wang, and H. Chang, "Modeling and optimization of air gap membrane distillation system for desalination," Desalination, vol. 354, pp. 68-75, 2014.

[6] H. Chang, G.-B. Wang, Y.-H. Chen, C.-C. Li, and C.-L. Chang, "Modeling and optimization of a solar driven membrane distillation desalination system," Renewable Energy, vol. 35, no. 12, pp. 27142722, 2010.

[7] H. Chang, S.-G. Lyu, C.-M. Tsai, Y.-H. Chen, T.-W. Cheng, and Y.-H. Chou, "Experimental and simulation study of a solar thermal driven membrane distillation desalination process," Desalination, vol. 286, pp. 400-411, 2012.

[8] R. Porrazzo, A. Cipollina, M. Galluzzo, and G. Micale, "A neural network-based optimizing control system for a seawater-desalination solar-powered membrane distillation unit," Computers \& Chemical Engineering, vol. 54, pp. 79-96, 2013.

[9] A. Plucenio, D. Pagano, A. Bruciapaglia, and J. Normey-Rico, "A practical approach to predictive control for nonlinear processes," IFAC Proceedings Volumes, vol. 40, no. 12, pp. 210-215, 2007.

[10] A. Pawlowski, J. L. Guzmán, F. Rodríguez, M. Berenguel, and J. E. Normey-Rico, "Predictive control with disturbance forecasting for greenhouse diurnal temperature control," IFAC Proceedings Volumes, vol. 44, no. 1, pp. 1779-1784, 2011.

[11] J. D. Gil, A. Ruiz-Aguirre, L. Roca, G. Zaragoza, M. Berenguel, and J. L. Guzmán, "Control de plantas de destilación por membranas con apoyo de enrgía solar-parte 1: Esquemas," in XXXVI Jornadas Automática, Bilbao, España, 2015.

[12] — - "Control de plantas de destilación por membranas con apoyo de enrgía solar-parte 2: Resultados," in XXXVI Jornadas Automática, Bilbao, España, 2015.

[13] A. Ruiz-Aguirre, D.-C. Alarcón-Padilla, and G. Zaragoza, "Productivity analysis of two spiral-wound membrane distillation prototypes coupled with solar energy," Desalination and Water Treatment, vol. 55, no. 10, pp. 2777-2785, 2015.

[14] J. D. Gil, A. Ruiz-Aguirre, L. Roca, G. Zaragoza, and M. Berenguel, "Solar membrane distillation: A control perspective," in Control and Automation (MED), 2015 23th Mediterranean Conference on. IEEE, 2015, pp. 796-802.

[15] L. Roca, M. Berenguel, L. Yebra, and D. C. Alarcón-Padilla, "Solar field control for desalination plants," Solar Energy, vol. 82, no. 9, pp. 772-786, 2008.

[16] J. A. Duffie and W. A. Beckman, "Solar engineering of thermal processes," 1980.

[17] A. de la Calle, L. Roca, J. Bonilla, and P. Palenzuela, "Dynamic modeling and simulation of a double-effect absorption heat pump," International Journal of Refrigeration, vol. 72, pp. 171-191, 2016.

[18] E. F. Camacho and C. B. Alba, Model predictive control. Springer Science \& Business Media, 2007.

[19] M. Castilla, J. Álvarez, J. Normey-Rico, and F. Rodríguez, "Thermal comfort control using a non-linear mpc strategy: A real case of study in a bioclimatic building," Journal of Process Control, vol. 24, no. 6, pp. 703-713, 2014.

[20] NIST. (2006) Engineering statistics handbook. url http://www.itl.nist.gov/div898/handbook/. 